\title{
Los inicios de la circulación pública de la creación musical escrita por mujeres en Chile ${ }^{1}$
}

\author{
The Beginnings of Public Circulation of Music Written \\ by Women in Chile
}

\author{
por \\ Luis Merino Montero \\ Facultad de Artes, Universidad de Chile \\ lmerino@uchile.cl
}

\begin{abstract}
Durante el período comprendido entre 1810 y 1855, en Chile la creación musical escrita por mujeres quedó absolutamente fuera del ámbito público. Por otra parte, en el período comprendido entre 1856 y 1869 dieciocho mujeres hicieron circular públicamente su obra, a las que se agregan otras tres mujeres que lo hicieron de manera anónima, hasta alcanzar un total de 39 obras publicadas. El objetivo prioritario del presente trabajo es explorar este proceso en cuanto a sus características principales y sus causas dentro de la sociedad civil chilena de la época. Dos factores son determinantes. Uno es el desarrollo de la educación sistemática de la mujer de la alta sociedad chilena, en la que el aprendizaje de la música jugó un papel clave. El otro factor es el desarrollo de la edición impresa y la distribución pública de la música que se produce en Chile a contar de la década de 1850, especialmente en los estratos altos de la sociedad de la época. Las compositoras, objeto de este estudio, se clasifican en tres grandes grupos, de acuerdo a las temáticas de la música que revelan o sugieren sus títulos, los propósitos de la publicación de la música, la vinculación de las creadoras con otras facetas de la música tales como la enseñanza y la interpretación y la asiduidad en el cultivo de la creación musical de acuerdo al número de obras publicadas en Chile. Todo el proceso transcurre en el momento que la sociedad civil se constituye, desde mediados del siglo XIX, como un componente independiente de la sociedad del país.
\end{abstract}

Palabras clave: Chile, sociedad civil, música del siglo XIX, tradición y modernidad, mujeres compositoras.

During the period ranging between the years 1810 and 1855 in Chile, music compositions written by women almost never circulated in public. On the other hand, during the period ranging between the years 1856 and 1869 , eighteen women had their works circulating in public, whereas three other women published their works anonymously. In all, no less than 39 works composed by women were published during this period. The main goal of this article is to explore this process as regards its main features and the causes within the Chilean civil society of the period. Two factors loom large as determinant. One is the developing of systematic education among women of the Chilean higher class, in which the study of music played a key rôle. The other factor has to do with the developing of music printing and the public distribution of music in Chile as of the decade of the 1850's, especially among the higher class. Women composers studied in this article are classified into three main groups, according to the subjects revealed or suggested by the titles of the works, the purpose of publishing the music, the relationship of the composers with such other areas of music as teaching and performance, and the assiduity in cultivating composition as revealed by the number of works published in Chile. This process occurs at a time when civil society becomes, as of the mid $19^{\text {th }}$ century, an independent part of the Chilean society at large.

Keywords Chile, civil society, music of the $19^{\text {th }}$ century, tradition and modernity, women composers.

${ }^{1}$ Este trabajo se ha realizado en el marco del proyecto de investigación Fondecyt N 1070927. 


\section{ANTECEDENTES, 1810-1855}

La sociedad chilena de la primera mitad del siglo XIX se caracteriza por una fuerte jerarquización y por estar estructurada en estamentos separados y en una relación de fuerte predominio de uno con respecto del otro. De acuerdo al musicólogo Rodrigo Torres esta situación "demarca un eje de continuidad del período colonial proyectado en la sociedad decimonónica"². En tal sentido, se advierten antípodas pronunciadas entre la Catedral, espacio en que tanto la creación como la interpretación musical son ejercidas por hombres exclusivamente, con la chingana, espacio en que la mujer tiene un papel clave en la recreación pública de una especie de tradición oral, la célebre zamacueca decimonónica, tanto en lo que respecta a sus dimensiones como canto y como baile ${ }^{3}$. Por otra parte, la mujer tiene también un importante accionar junto al hombre en el teatro durante este período, como un espacio complejo en que se entreveran inicialmente el drama y la comedia, a los que se agregan ulteriormente la ópera, la danza y las presentaciones de música instrumental y vocal ${ }^{4}$.

La creación musical escrita por una mujer durante este período encuentra como su nicho la intimidad del hogar familiar. Tal es el caso de la gran dama de la música decimonónica chilena Isidora Zegers, cuya "obra musical estuvo pensada para su propio uso y goce y, posiblemente, para ser compartida con sus seres más cercanos, ligados a ella por lazos de parentesco y amistad. Por ello, la preservación de su obra musical fue un asunto de familia, no un tema público"5. No obstante, esta faceta, sumada a lo que siguiendo a Pilar Ramos se puede denominar como el "patronazgo y activismo musical" de Isidora Zegers, se constituyó en una gran novedad en su época, de acuerdo al testimonio de una hija del primer matrimonio de Isidora Zegers, Flora Tupper de Bianchi ${ }^{6}$ :

"En 1823, mi madre joven, tocando y cantando bien, y hablando perfectamente el francés, y algo de italiano, debió ser y fué en realidad considerada como una notabilidad. Las chilenas de su época eran por lo general niñas dotadas de talento natural, pero sumamente ignorantes, y muchas había que ni firmar su nombre sabían".

De aquí que Isidora Zegers junto a su madre transformaran su hogar en un punto de atracción para la juventud de la época ${ }^{7}$ :

"En mi vida privada, mamá no se divertía menos. Mi abuela recibía a la mejor sociedad de Santiago, pues toda la juventud de aquel entonces se sentía atraída hacia aquellas dos mujeres de educación e índole tan diversas a la de las señoras del país. La amabilidad y belleza de la madre, la viveza y talento musical de la hija, y preciso es decirlo, la coquetería de ambas mujeres, traía locos a todos los chilenos jovenes en 1823, acos-

\footnotetext{
${ }^{2}$ Cf. Torres 2008: 6.

${ }^{3}$ Cf. Torres 2008.

${ }^{4}$ Cf. Torres 2008 y Merino 2006.

${ }^{5}$ Merino 2008: 53.

${ }^{6}$ Tupper de Bianchi s.f.: 51.

${ }^{7}$ Tupper de Bianchi s.f.: 59-60.
} 
tumbrados como estaban entonces al apocamiento y ninguna ilustración de la mujer chilena de aquella época”.

Además de la música, Isidora Zegers demostró desde su más tierna infancia, según su hija Flora, "una pasión loca por el teatro". 8 Por ello, continúa, la intención de su padre había sido "dedicar a su hija al teatro"9. En esta faceta y en muchas otras, Isidora Zegers, según su hija, se diferenció de las mujeres chilenas de su época. A este respecto, se puede señalar su actitud hacia los quehaceres domésticos, que se consideraban por la sociedad chilena de la época como consustanciales al ser y el quehacer de la mujer ${ }^{10}$ :

"En cuanto a costura, cocina, no solo carecía mi madre hasta de la menor noción de esa clase de trabajos tan necesarios en la mujer, sinó que se oponía a que sus hijas las aprendieran y se incomodaba cuando oía alabar alguna otra mujer de diestra de manos para la aguja y sobre todo para la cocina o repostería, que ella calificaba de trabajos vulgares y solo capaces de entretener a tontas y golosas amigas de comistrajos".

Fue en el tipo de salones que prohijara Isidora Zegers y su madre que la música cumplió un papel muy importante como práctica social, en la que se destaca la participación de la mujer como intérprete. En tal sentido, los inicios de la actividad de conciertos públicos en Chile, durante la década de 1820, constituyen una proyección al ámbito público de la actividad privada en el salón. Fundamental en este respecto es la Sociedad Filarmónica de Santiago que floreció entre 1826 y 1828, como una instancia de sociabilidad para hombres y "señoritas", en la que le cupo a la mujer un importante papel como intérprete musical ${ }^{11}$.

No obstante, y con la excepción de Isidora Zegers, cuya obra se comunicó dentro del ámbito privado, según ya se ha señalado, los restantes compositores del período, tanto chilenos como extranjeros, fueron varones. Paradojalmente, un destinatario importante de sus obras fueron las mujeres, quienes sí tuvieron un papel determinante en el cultivo de la música como práctica social.

A modo de ejemplo se puede hacer mención a las únicas obras de Enrique (=Enrico) Lanza de las que se tiene referencia documentada. Lanza, nacido en Londres en 1810 de padres italianos y con estudios en París, es una de las figuras preeminentes en la sociedad civil de Chile durante la década de 1840, después de su efímero paso por la maestría de capilla de la Catedral de Santiago. Las obras fueron reunidas en el Álbum Musical. En El Progreso, I/33 (19 de diciembre, 1842), p. 4, c. 1, el anuncio señala que se compone de dos romances en italiano y dos en español, dos contradanzas, un valse y una “canción nacional”. Se informa su aparición a contar del 1 de enero de 1843, mientras que las suscripciones se reciben en el local del litógrafo José Desplanques, en calle Ahumada [ $\left.\mathrm{N}^{\circ} 22\right]$, media cuadra antes de "la cañada" o la Alameda de Santiago" ${ }^{12}$. El mismo diario, I/27 (12 de

\footnotetext{
${ }^{8}$ Tupper de Bianchi s.f.: 19.

${ }^{9}$ Tupper de Bianchi s.f.: 30.

${ }^{10}$ Tupper de Bianchi s.f.: 32-33.

${ }^{11}$ Cf. Merino 2006: 8,10, 13.

${ }^{12}$ Un facsímil de la portada aparece en Pereira Salas 1978: 90.
} 
diciembre, 1842), pp. 1-2, señala que publicaciones como este Álbum tenían como usuario principal a las damas, en un espacio privado fuera del alcance masculino:

\begin{abstract}
"Ahora hai otra novedad albúmica que en el país hace ciertamente época. Tenemos por ahí anunciado un album musical, compuesto por el Sr. Lanza. Eso sí que es progreso, difusión de las luces y adelanto no como quiera. Eso sí; los jóvenes sabrán lo que quieran en materia de letras, pero en cuanto a lo musical no somos capaces de comprender ni el chirrido de una carreta. Eso es en Chile el domino exclusivo de las bellas.

"El album musical es su propiedad y ni por un momento teman que nadie de nosotros vaya a urguetearles el catálogo de piezas. Cuando quieran ocultar un billetito u otro instrumento de autos, ponganlo en un Album musical y digan que se lo ha comido la tierra, que lo han puesto bajo cuatro llaves, o que lo andan trayendo en el seno. Ni la mamá, ni la turba de curiosos llegarían a penetrar en aquel Sancto Sanctorum".
\end{abstract}

En contraste con el período comprendido entre 1810 y 1855 , en que la creación musical escrita por mujeres quedó absolutamente fuera del ámbito público, en el período comprendido entre 1856 y 1869 dieciocho mujeres hicieron circular públicamente su obra, a las que se agregan otras tres mujeres que lo hicieron de manera anónima, hasta alcanzar un total de 39 obras publicadas. E1 objetivo prioritario del presente trabajo es explorar este proceso en cuanto a sus principales características y causas dentro de la sociedad civil chilena de la época.

\title{
PERÍODO 1855-1869
}

Isidora Zegers constituye una personalidad que enlaza estos dos períodos de la historia de la música en Chile. Hasta su fallecimiento, el 13 de julio de 1869, ella mantuvo incólume su actividad en conciertos con los músicos más destacados del medio, y como estimuladora de la vida social y cultural. Para este efecto continuó con las reuniones que realizara en su casa, lugar en el que se presentaban todos los artistas que visitaban la capital antes de ofrecer conciertos públicos. Los múltiples homenajes que se le realizaron con ocasión de su fallecimiento apuntaban a un reconocimiento de ella como un referente para una tradición de la música chilena decimonónica, desde una perspectiva de una sociabilidad en cuanto al modo de hacer música ${ }^{13}$, el que se sustenta, de acuerdo a los términos de Pilar Ramos, en un patronazgo y activismo musical femenino como base de una presencia pública.

La raíz del accionar de esta gran dama era una episteme adquirida en Europa. Por otra parte el país atravesaba un proceso de cambio que se entronca, por una parte, con el proyecto emancipador de la modernidad, y, por la otra, con la gradual implementación en Chile de un modelo liberal, en lo político y en lo social, que conduce, el año 1861, al advenimiento del candidato liberal José Joaquín Pérez a la Presidencia de la República.

${ }^{13} \mathrm{Al}$ respecto $c f$. Merino 2009. 
En este proceso, un factor determinante es la educación sistemática de la mujer de la alta sociedad chilena. Si bien la educación fue un proceso que se realizaba de manera separada para los hombres y para las mujeres, fue hacia finales de la década de 1820 que se establecen en Santiago los primeros "colejios de señoritas"14. Durante una gran parte del siglo XIX la enseñanza de la música a nivel escolar fue una tónica de los colegios femeninos, no así de los colegios masculinos, lo que indudablemente guarda relación con la consideración de la música como "el dominio exclusivo de las bellas".

A modo de ejemplo se puede citar el caso del Colegio de las Señoras Pineda. De acuerdo a El Progreso, IV/980 (sábado 3 de enero, 1846), p. 2, cc. 1-3, la labor de este establecimiento educacional se evalúa en los siguientes términos:

"El Colejio de las señoras Pinedas podemos considerarlo como uno de los establecimientos mas aventajados qe Chile posee, para la enseñanza femenil. La educacion no esta en él circunscrita a las meras artes de adorno; alli se las educa para la sociedad i la familia al mismo tiempo qe se ensancha su intelijencia adornándola con todos aqellos conocimientos qe oi dia son necesarios a una jóven, se forma su corazon preparándolas para el ogar doméstico".

Entre estos "conocimientos" se mencionan los siguientes: escritura (dos niveles), gramática castellana, francés (dos niveles), geografía, aritmética, dibujo (dos niveles), piano, canto, baile, cuadros bordados. La importancia de la enseñanza de la música puede aquilatarse en el nivel de los profesores que la enseñaban y las presentaciones de fin de año, que consistían en verdaderos conciertos públicos, de los que existe documentación más allá de la primera mitad del siglo XIX.

Esta práctica continuó en el período comprendido entre 1855 y 1869. Figuras del calibre de un Inocencio Pellegrini enseñaban canto el año 1866 en el Colegio de Señoritas dirigido por Bruna Venegas de Riquelme ${ }^{15}$. Otro tanto hacía el destacado pianista alemán Guillermo (=Wilhelm) Deichert como profesor de piano del Colegio Alemán para Señoritas en $1865^{16}$. Ambos, junto a muchos otros profesores, impartieron enseñanza musical además a nivel más especializado, para lo cual contaron con numerosas estudiantes mujeres. A modo de ejemplo se puede señalar una Mis a coral de Inocencio Pellegrini, entonada durante la Fiesta de Corpus Christi de 1866, en la Parroquia de La Estampa, por varias de sus "mas distinguidas alumnas"17. Cabe agregar el nombre del músico italiano Giovanni Bayetti (1811-1876), calificado por el eminente historiador Eugenio Pereira Salas como "el profesor de mayor influencia" en este período desde "el punto de vista social" 18 , quien a contar de 1853 comenzó a presentar a sus estudiantes en público, entre los cuales se contaban muchas mujeres pertenecientes a la alta burguesía de la época ${ }^{19}$.

\footnotetext{
${ }^{14} \mathrm{Al}$ respecto $c f$. Merino 2006: 14-15.

${ }^{15}$ Cf. Merino 2009.

${ }^{16}$ Cf. Merino 2009.

${ }^{17}$ El Ferrocarril, XI/3.256 (viernes 8 de junio, 1866), p. 3, c. 5.

${ }^{18}$ Pereira Salas 1957: 96.

${ }^{19}$ Pereira Salas 1957: 106.
} 
Este poderoso y sistemático desarrollo de la educación musical femenina, tanto en lo que respecta a la formación escolar como al estudio más especializado, permitió que un número significativo de mujeres se adentrara en la creación musical y diera a conocer su obra en un ámbito público.

El presente trabajo cubre la fase de inicio de este proceso, que se extiende entre 1856 y 1869. Comprende tres obras anónimas, además de treinta y seis obras escritas por las siguientes compositoras, ordenadas en orden alfabético por su apellido paterno en la tabla $\mathrm{N}^{\circ} 1$, junto al número de obras públicas de cada una.

TABLA $N^{\circ} 1$

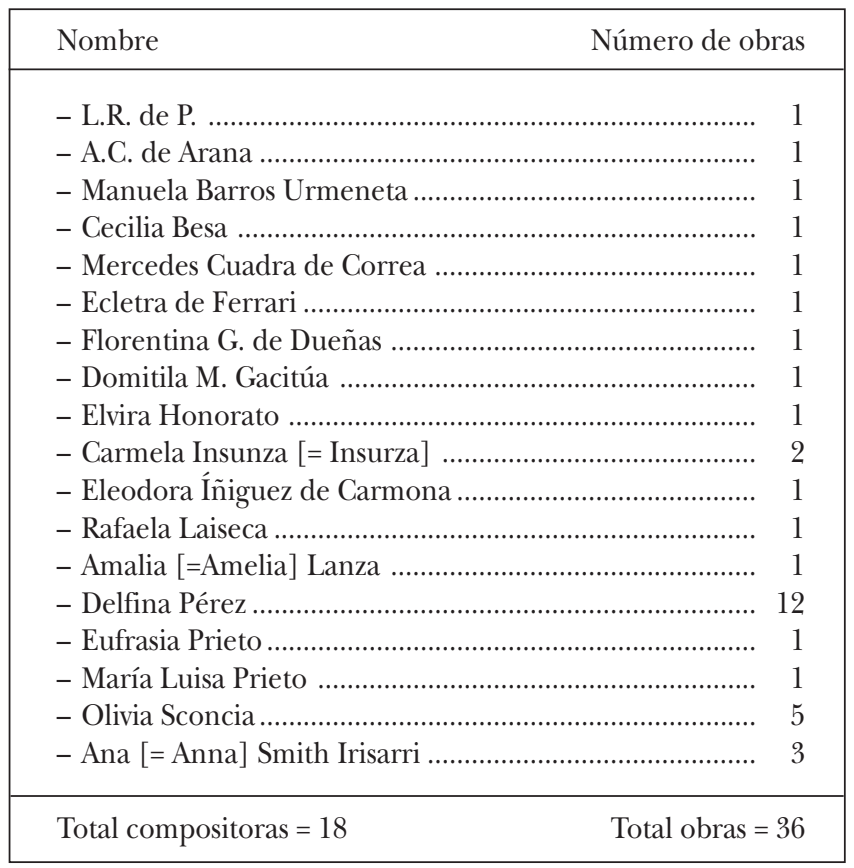

Además de la educación, contribuyó poderosamente a la circulación de la música creada por mujeres el desarrollo de la edición impresa y la distribución pública de la música que se produce en Chile a contar de la década de 1850. Para este efecto se señala en la tabla $\mathrm{N}^{\circ} 2$ un listado en orden alfabético, de acuerdo a las abreviaturas asignadas, de las casas que editaron y/o distribuyeron la música compuesta por las compositoras que se consideran en el trabajo. 


\section{TABLA No 2}

\section{CASAS EDITORAS Y/O DISTRIBUIDORAS}

\begin{tabular}{|ll|}
\hline AE & Valparaíso, Almacén de Música de Augusto Eggeling. \\
AF & Santiago, Agencia del Ferrocarril, Calle de los Huérfanos. \\
AS & Santiago, Litografía de A. Saling, Plaza del Teatro. \\
BA & Santiago, Periódico Las Bellas Artes. \\
CL & Santiago, Periódico El Correo Literario \\
EG & Santiago, Litografía y Almacén de Eustaquio Guzmán, Pasaje Bulnes No 47. \\
FG & Santiago, Litografía de Fernando Guzmán. \\
IP & Santiago, Tienda de Inocencio Pellegrini. \\
JK & Santiago, Almacén de Música Juan Krause, Portal Viejo, Calle del Estado. \\
LMA & Valparaíso, La Mariposa, "periódico quincenal de modas, costumbres i amena \\
& literatura". \\
LME & Valparaíso, Librería del Mercurio. \\
LSV & Valparaíso, Litografía Lebas Sucesor. \\
NA & Santiago, Nicolás Anrique, Calle de la Compañía, No 81. \\
NIS & Santiago, Almacen de Música Niemeyer e Inghirami, Calle del Estado. \\
NIV & Valparaíso, Almacén de Música Niemeyer e Inghirami, Calle del Cabo ํo 17. \\
PC & Santiago, Liografía de Pedro [=Pierre André] Cabot, Calle del Estado № 40, frente a \\
& la Galería Bulnes. \\
RPS & Santiago, Almacén Francisco Risso Patrón, Calle de los Huérfanos No 190. \\
RPV & Valparaíso, Almacén Baldomero Risso Patrón, Calle del Cabo. \\
TS & Santiago, Tienda del Sr. Sémier.
\end{tabular}

En la tabla $\mathrm{N}^{\circ} 3$ se indican en la línea horizontal estas casas editoras y/o distribuidoras de música, mientras que en la línea vertical se señalan las obras ordenadas en forma cronológica. Se excluyen aquellas obras sin editor o distribuidor conocido. Se emplean las abreviaturas "ed" para editor y "dist" para distribuidor.

Se destaca la importancia que tienen las casas editoras/distribuidoras a cargo de Eustaquio Guzmán (EG) y el Almacén de Música Niemeyer e Inghirami en Santiago (NIS) y Valparaíso (NIV). En comparación con las restantes casas señaladas en la tabla $\mathrm{N}^{\circ} 3$, estas dos últimas son las que mayormente editaron y/o distribuyeron la creación musical escrita por este grupo de compositoras mujeres. La música se imprimió mediante un proceso litográfico, el que se utilizó en Chile hasta mediados de la década de 1870, cuando fue sustituido por el procedimiento industrial del fotograbado ${ }^{20}$.

Las casas a cargo de Niemeyer e Inghirami y Eustaquio Guzmán representan las dos antípodas en que se enmarca la impresión y distribución de la música en Chile, en el período del ocaso del régimen político conservador y el advenimiento del liberalismo como fuerza política mayoritaria en el país. La casa Niemeyer e

\footnotetext{
${ }^{20}$ Pereira Salas 1957: 359.
} 


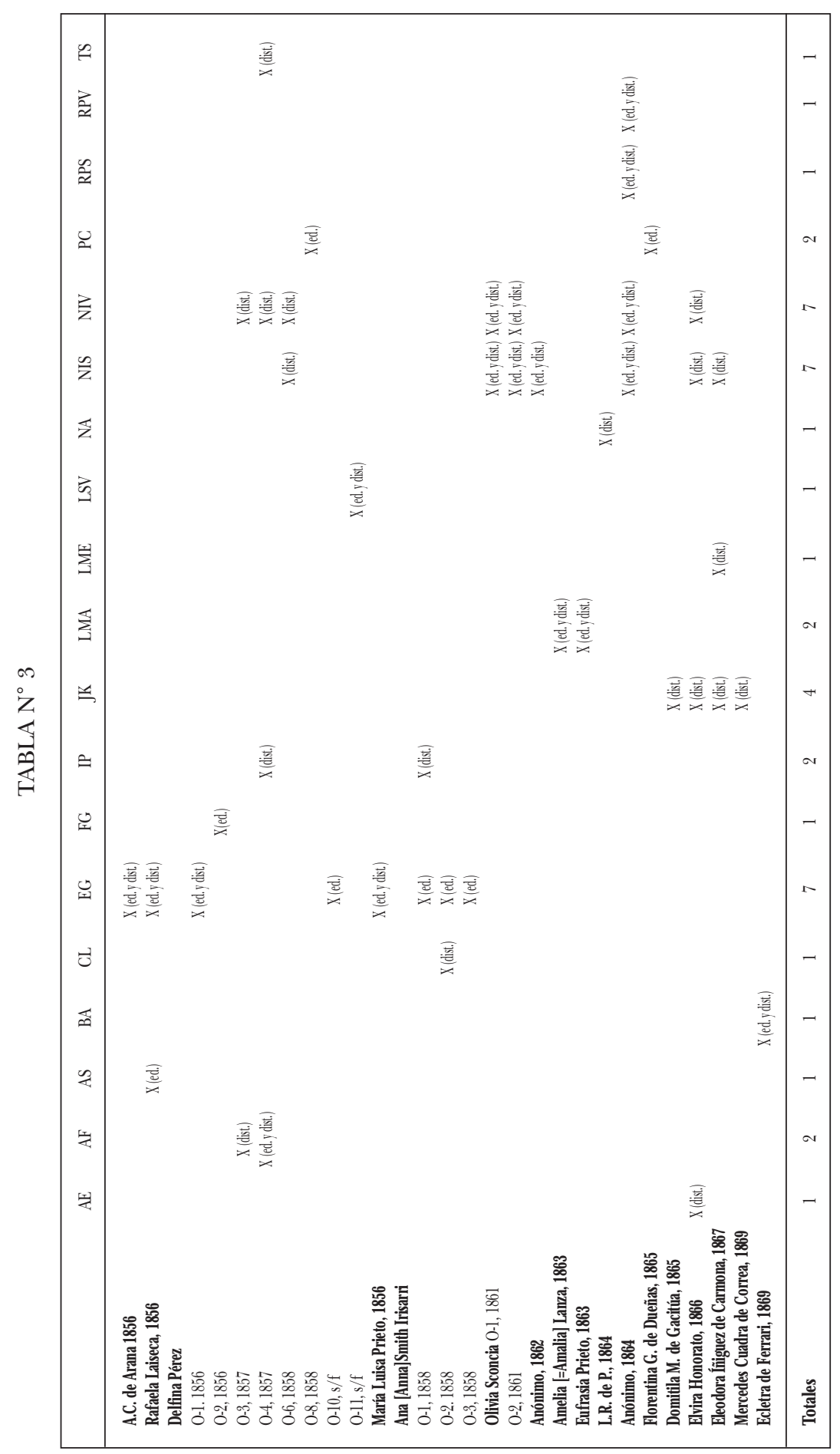


Inghirami fue comanditaria de la empresa Niemeyer e Inghirami, con sede en Hamburgo y sucursal en Lima ${ }^{21}$. Esto permitía un mayor tiraje de ejemplares de la música conjuntamente con la posibilidad de tener una mejor distribución. A modo de ejemplo, el valse Armando il gondoliero de Delfina Pérez [O-6, 1858] fue editado en Alemania en una tirada de quinientos ejemplares ${ }^{22}$, presumiblemente por la empresa Niemeyer e Inghirami.

Por otra parte, Eustaquio Guzmán representa la edición y distribución de la música a nivel nacional. Fueron notables en tal sentido sus esfuerzos para poner su empresa a un nivel competitivo. Al respecto, El Ferrocarril III/787 (martes 6 de julio, 1858), p. 3, c. 5, informa que su establecimiento acababa "de recibir de Europa los elementos necesarios para ponerlo en un pié brillante". Por ello era felicitado en esta nota de prensa "por su empeñosa laboriosidad para vencer los obstáculos que se presentan para la planteacion de una nueva industria" en el país.

Junto a la calidad técnica, se destaca en el caso de Eustaquio Guzmán su imaginación para idear colecciones que pudieran ser atractivas para el público comprador, especialmente el femenino. Tal es el caso del Album Musical de Señoritas que inició sus actividades en 1856. La polka La luna de invierno de A.C. de Arana fue publicada ese año como el número $8^{23}$. Por su parte, la polka La simpatía de María Luisa Prieto fue publicada ese año como el número $12^{24}$. Ambas constituyen las primeras obras en el país escritas por mujeres y publicadas para una audiencia preeminentemente femenina.

En todo caso, cabe agregar que estas antípodas no fueron excluyentes, puesto que en algunos casos la música impresa por Eustaquio Guzmán se distribuía en Santiago y Valparaíso por Niemeyer e Inghirami junto a otras casas distribuidoras ${ }^{25}$.

Junto a Eustaquio Guzmán, su hijo Fernando (FG) también publicó música escrita por mujeres, entre los editores locales. A ambos se agregan las otras casas editoras y/o distribuidoras que se señalan en la tabla $\mathrm{N}^{\circ} 2$, ubicadas tanto en Santiago como en Valparaíso, y que fueron regentadas por chilenos o por extranjeros residentes en el país.

Las compositoras, objeto de este estudio, se clasifican en tres grandes grupos.

El primer grupo corresponde a aquellas mujeres que, aparte de las obras publicadas, no evidencian otra vinculación con la música como actividad pública. En términos de "visibilidad", siguiendo en el uso del término a Pilar Ramos, tres obras fueron publicadas anónimamente. Dos de ellas aluden al valor social de la amistad. Se trata del Último adiós, gran valse para piano publicado en 1862 por "una señorita" que lo dedicara a Guillermo Lees ${ }^{26}$. Otra es El voluntario, publicado en 1864, y anunciado como un "valse dedicado a la entusiasta juventud de Santiago i Valparaiso, compuesto por una señorita hija de un veterano de la Independencia" ${ }^{27}$. La terce-

\footnotetext{
${ }^{21}$ Cf. Pereira Salas 1957: 358.

${ }^{22}$ El Ferrocarril, III/633 (martes 5 de enero, 1858), p. 3, c. 2.

${ }^{23}$ El Ferrocarril, I/219 (jueves 4 de septiembre, 1856), p. 3, c. 6.

${ }^{24}$ El Ferrocarril, I/283 (viernes 21 de noviembre, 1856), p. 3, c. 2.

${ }^{25} \mathrm{Al}$ respecto cf. El Correo Literario, I/15 (sábado 23 de octubre, 1858).

${ }^{26}$ El Ferrocarril, VII/2153 (miércoles 3 de diciembre, 1862), p. 3, c. 3.

${ }^{27}$ El Ferrocarril, IX/2662 (viernes 8 de julio, 1864), p. 3, c. 3.
} 
ra obra tiene un contenido patriótico y se titula El suspiro de la Italia o la muerte de Cavour y fue publicada en 1861. La autora es descrita como "una señorita de esta capital, entusiasta por la Independencia de la Italia, i admiradora del gran patriota que esta nación acaba de perder" 28 . En el caso de la polka La aristócrata, publicada en 1864, la autora no deja entrever una intencionalidad específica pero dejó por lo menos las iniciales de su nombre, L. R. de P. ${ }^{29}$.

Las restantes obras de este primer grupo son de autoras con nombre conocido. Aparte de su tipología como música de salón las obras publicadas en 1856 por A.C. de Arana y en 1869 por Ecletra de Ferrari y Mercedes de la Cuadra de Correa no trasuntan a través de sus títulos mayores evidencias respecto de sus contenidos. Por otra parte, las obras publicadas por las restantes compositoras de este primer grupo sí manifiestan una intencionalidad específica en lo que respecta a su comunicación pública.

Tres obras, publicadas entre 1865 y 1866, tienen una clara intencionalidad patriótica, toda vez que guardan relación con la guerra que sostuviera Chile con España entre 1865 y 1866. En tal sentido, Florentina G. de Dueñas dedica su vals para piano La Esmeralda, publicada en 1865, al comandante Juan Williams Rebolledo, vencedor de la Covadonga, junto con destinar los dineros recaudados por la venta de la obra pro fondos de la guerra ${ }^{30}$. Un idéntico dedicatorio y propósito tuvo el Schottisch para piano publicado en 1866 por Elvira Honorato a los 14 años de edad ${ }^{31}$. Asimismo, la publicación en 1865 de Alerta, polka mazurka para piano de Domitila M. Gacitúa, anunciada como el primer ensayo de la compositora, también tuvo el destino de recaudar fondos para esta guerra ${ }^{32}$.

En dos obras se plantea una intencionalidad más bien política. Tal es el caso de la polka La constitución granadina de Rafaela Laiseca, publicada por la litografía de Eustaquio Guzmán (EG) a fines del año 1856 y que fue puesta a la venta por el precio de 50 centavos el ejemplar ${ }^{33}$. En cambio la polka para piano rotulada $L a$ dictadura peruana y publicada en 1866 por la aficionada Carmela Insunza (=Insurza) se vincula al mundo político del Perú, toda vez que se anunció como una "obra dedicada al señor don Mariano Ignacio Prado, dictador del Perú ${ }^{34}$. Incluso ella le hizo llegar una carta a Prado, presumiblemente con la obra, la que este último le respondió con sus agradecimientos ${ }^{35}$.

En tal sentido, esta última obra puede comprenderse como un reconocimiento a este militar y político peruano, nacido en Huánuco en 1826 y fallecido en París en 1901, quien al abrupto término de su primer período como Presidente de la República del Perú (1865-1868) regresó a Chile, país en el que había residi-

${ }^{28}$ El Ferrocarril, VI/1740 (lunes 5 de agosto, 1861), p. 3, c. 2.

${ }^{29}$ Ver en el Catálogo, Anónimo, 1864.

${ }^{30}$ El Ferrocarril, X/3101 (jueves 7 de diciembre, 1865), p. 3, c. 4.

${ }^{31}$ El Ferrocarril, X/3131 (11 de enero, 1866), p.3, c.6. y El Ferrocarril, XI/3132 (viernes 12 de enero, 1866), p. 3, c. 3 .

${ }^{32}$ El Ferrocarril, X/3081 (martes 14 de noviembre, 1865), p. 3, c. 3.

${ }^{33}$ El Ferrocarril, I/292 (martes 2 de diciembre, 1856), p. 3, c. 6.

${ }^{34}$ El Ferrocarril, XI/3427 (sábado 22 de diciembre, 1866), p. 3, c. 4.

${ }^{35}$ De acuerdo a El Ferrocarril, XII/3460 (jueves 24 de enero, 1867), p. 3, c. 2. 
do en 1853 a raíz de su anterior deportación del Perú. En Chile, Prado se dedicó al negocio del carbón, que le permitió amasar una respetable fortuna, la que sin duda sustentó su figuración entre "los primeros capitalistas" que se incorporaron a la importante Sociedad Orfeón en 1869, y de la que llegó a ser su presidente en noviembre de dicho año ${ }^{36}$.

En un similar tenor Cecilia Besa, "una señorita aficionada”, publicó en 1864 la polka mazurka La Salvadora, dedicada a la Primera Compañía de Bomberos ${ }^{37}$, una institución que se engarza en el ideario liberal del Chile de la época ${ }^{38}$, a la que también se vincularon muchos músicos del Chile decimonónico ${ }^{39}$. Por otra parte, la Salve a la Virgen de Manuela Barros Urmeneta se vincula con el mundo religioso y fue interpretada el viernes 8 de noviembre de 1861 por el entonces joven músico Osbaldo Uriondo en la celebración del Mes de María en la Iglesia de la Compañía ${ }^{40}$.

La vinculación de estas obras del primer grupo de compositoras con asuntos patrióticos, políticos, religiosos, o con instituciones de servicio público de la sociedad civil chilena tales como el Cuerpo de Bomberos conforman una inserción de la mujer en el espacio público de esta época que va más allá de la circulación pública de su obra creativa. De acuerdo a Carlos Sanhueza, la inserción de la mujer en el espacio público en esta época extrapolaba la esfera doméstica, privativa de la mujer, a la esfera de la pólis, privativa entonces del hombre, en un actuar educativo y benefactor ${ }^{41}$. De ahí que las obras escritas por mujeres con ocasión de la guerra que Chile librara con España se pueden entender como una contribución femenina a la defensa de la patria amenazada, de modo de proteger la integridad de la familia y los hijos. Algo similar se puede señalar respecto al Cuerpo de Bomberos, institución creada en Valparaíso el año 1851, después de un grave incendio acaecido el año anterior en el centro del barrio del "Puerto" 42 , y en Santiago el 8 de diciembre de 1863, a raíz del incendio que destruyó la Iglesia de la Compañía de Jesús ${ }^{43}$. De ahí se puede entender el título de La Salvadora, que Cecilia Besa utiliza para la mazurka que dedicara a la Primera Compañía de Bomberos. Esto, a su vez, se puede relacionar con el "aspecto civil más que político" de la inserción de la mujer en el espacio público de Chile en esta época ${ }^{44}$.

El segundo grupo abarca aquellas mujeres que, además de la creación, tuvieron una vinculación con otras facetas de la música, tales como la enseñanza y la interpretación. En sus obras no se advierte una intencionalidad política o patriótica, o que guarde relación con instituciones de servicio público pertenecientes a la sociedad civil, que se señalara para el caso de las autoras del primer grupo, sino

\footnotetext{
${ }^{36} \mathrm{Al}$ respecto, $c f$. Merino 2009: 20.

${ }^{37}$ El Ferrocarril, IX/2621 (sábado 28 de mayo, 1864), p. 2, c. 6, p. 3, c. 1.

${ }^{38}$ Cf. Gazmuri 1992: 185-212.

${ }^{39}$ Cf. Merino 1993: 19.

${ }^{40}$ El Ferrocarril, VI/1819 (viernes 8 de noviembre, 1861), p. 3, c. 3.

${ }^{41}$ Sanhueza 2005: 334.

${ }^{42}$ Gazmuri 1992: 186.

${ }^{43}$ Gazmuri 1992:188.

${ }^{44}$ Sanhueza 2005: 335.
} 
que más bien las compositoras del segundo grupo exaltan, a través de su música, valores tales como la amistad, la filantropía o la poesía.

De este segundo grupo, dos hermanas, María Luisa Prieto, una "distinguida dama de la sociedad”, según Eugenio Pereira Salas ${ }^{45}$, y Eufrasia Prieto, tomaron parte como cantantes en los conciertos de beneficencia que dirigiera su maestro Bayetti $^{46}$, y publicaron sendas obras en 1856 y $1863^{47}$. En 1856 María Luisa Prieto residía en Valparaíso ${ }^{48}$, ciudad en la que también residieron las restantes dos miembros de este grupo, Amelia (=Amalia) Lanza y Eleodora Íñiguez de Carmona.

Amelia Lanza fue hija del compositor Enrique Lanza, mencionado anteriormente, y se desempeñó como profesora de piano en Valparaíso ${ }^{49}$, además de ser uno de los "elementos indispensables en los conciertos" que se efectuaban en dicha ciudad ${ }^{50}$. El domingo 23 de diciembre de 1866 participó en una función de despedida de su padre realizada en Valparaíso con la participación, entre otros artistas, del célebre pianista norteamericano Louis Moreau Gottschalk. Con este último Amelia Lanza interpretó la "Fantasía sobre temas de la ópera Marta", para dos pianos, "compuesta espresamente para esta funcion por el Sr. Gottschalk", y la "Gran polka de concierto para dos pianos compuesta por el Sr. Gottschalk" 11 .

Eleodora Íñiguez de Carmona publicó en 1867 el vals rotulado El poeta. Inicialmente se anunció como una obra "dedicada al distinguido vate chileno don Eduardo de la Barra, por una señorita porteña"52. Posteriormente, otra nota de prensa señalaba que la obra es un obsequio "a nuestro elegante poeta don Eduardo de la Barra con motivo de unos versos que éste le había dedicado el año anterior" ${ }^{25}$. Estos versos se escribieron con motivo del debut de Eleodora Íñiguez de Carmona en el concierto que el pianista norteamericano Louis Moreau Gottschalk ofreciera en Valparaíso el domingo 9 de diciembre de 1866. Al respecto se señaló lo siguiente por el diario El Mercurio de Valparaíso el día anterior a la realización del concierto ${ }^{54}$.

"El sr. Gottschalk va a presentar al pueblo de Valparaiso a la mas brillante de sus discípulas, cuyo talento encomia el insigne maestro como uno de los soles luminosos que asoman en el horizonte americano. Precedida de una envidiable reputacion, aclamada por uno de nuestros poetas mas populares [Eduardo de la Barra], la Sra. Eleodora Iñiguez de Carmona permanece sin embargo desconocida para el publico porteño".

${ }^{45}$ Pereira Salas 1978:105. Cf. además, Pereira Salas 1957: 368, 369.

${ }^{46}$ Pereira Salas 1978: 105.

${ }^{47}$ Ver Catálogo.

${ }^{48}$ El Ferrocarril I/283 (viernes 21 de noviembre, 1856), p. 3, c. 2.

${ }^{49}$ Pereira Salas 1957:257, n.2. En los periódicos consultados el nombre aparece como Amelia o Amalia. La primera forma de indicar el nombre aparece con mayor frecuencia que la segunda.

${ }^{50}$ Pereira Salas 1957: 320.

${ }^{51}$ El Mercurio, Valparaíso, XXXIX/11.841 (viernes 21 de diciembre, 1866), p. 3, c. 5.

${ }^{52}$ El Ferrocarril, XII/3572 (sábado 18 de mayo, 1867), p. 3, c. 6.

${ }^{53}$ El Ferrocarril, XII/3587 (domingo 2 de junio, 1867), p.2, c.5. El nombre de la artista se señala como "Eleodora" en la prensa de la época, no como "Eleonora" según aparece en Pereira Salas 1957: 104,365 .

${ }^{54}$ El Mercurio, Valparaíso, XXXIX/11.830 (sábado 8 de diciembre, 1866), suplemento, p. 2 , c.1. 
El aprecio que Gottschalk tenía del talento pianístico de la artista se revela en la participación de Eleodora Íñiguez de Carmona en cuatro de los ocho números de este concierto, que se realizara a beneficio del Hospital y del Asilo del Buen Pastor y que fuera dedicado a la Ilustre Municipalidad de Valparaíso ${ }^{55}$. La actuación de Eleodora Íñiguez de Carmona tuvo gran eco en los comentarios publicados el 11 de diciembre acerca del concierto ${ }^{56}$.

El tercer grupo se emparienta con el segundo grupo, en lo que respecta a una vinculación más estrecha con la música en cuanto praxis pública en contraste a lo que concierne a las integrantes del primer grupo. No obstante, se diferencia de ambos en cuanto sus integrantes revelan una intencionalidad de vincularse de manera más permanente con la música como praxis creativa, de acuerdo al número de obras publicadas. Una primera evidencia de esta intencionalidad es el número de obras que publicaron las compositoras que se han adscrito a este grupo. De acuerdo a lo señalado en la tabla $\mathrm{N}^{\circ} 1$, Ana [Anna] Smith Irisarri publicó tres obras (1858), Olivia Sconcia publicó cinco obras (1861), mientras que Delfina Pérez publicó doce obras (1856-1875) ${ }^{57}$.

Ana [Anna] Smith Irisarri fue discípula del célebre pianista y compositor chileno Federico Guzmán ${ }^{58}$, presumiblemente entre 1857 y 1866, período en que este último ofreció públicamente sus servicios como profesor de piano ${ }^{59}$. Es muy posible que haya sido Federico Guzmán quien animara a Ana Smith Irisarri a publicar tres de sus obras el año 1858 a través de la litografía de su padre Eustaquio Guzmán (EG). Dos de estas obras son para piano, La sonrisa, polka elegante [O-1], y La pensativa, polka mazurka [O-3]. La tercera obra [O-2] es una canción, La separación, que apareció como suplemento musical de El Correo Literario, I/5 (14 de agosto, 1858), y figura entre las primeras obras vocales escritas sobre un texto del importante escritor decimonónico chileno Guillermo Blest Gana. Por otra parte, esta canción ilustra otras dos de sus facetas, la de cantante, discípula posiblemente de Inocencio Pellegrini ${ }^{60}$, y la de animadora de "interesantes tertulias artísticas y musicales entre los años 1858 a 1875" con su hermano, el paisajista

${ }^{55}$ De acuerdo a El Mercurio, Valparaíso, XXXIX/11.830 (sábado 8 de diciembre, 1866), p. 3, c. 5, las cuatro obras fueron las siguientes: (1) Gran fantasía sobre temas de la Lucia para dos pianos, por Ana Eleodora (su nombre completo) Íñiguez de Carmona y Gottschalk; (2) Elejia para flauta y piano de Ernst con Juan Jacobo Thompson; (3) Fantasia para piano sobre temas de la Traviata por Goria de piano solo; (4) Las harpas chilenas, Fantasia sobre la zamacueca para piano solo del compositor chileno Santiago Heitz.

${ }^{56}$ El Mercurio de Valparaíso, XXXIX/11.832 (martes 11 de diciembre, 1867), p. 2, c.7; en p. 3, c. 1, aparece otro poema laudatorio de M.A. Hurtado.

${ }^{57}$ Ver Catálogo.

${ }^{58}$ Cf. Pereira Salas 1957: 369.

${ }^{59}$ Cf. Merino 1993: 21, n. 80, 81.

${ }^{60}$ En El Ferrocarril, III/775 (martes 22 de junio, 1858), p. 3, c. 3, se la califica como "una de las mas distinguidas cantatrices de nuestros conciertos de beneficencia”, de los cuales existen registros en $\mathrm{El}$ Ferrocarril, III/858 (miércoles 29 de septiembre, 1858), p. 2, c. 7, y El Ferrocarril, IV/1239 (jueves 22 de diciembre, 1859), p. 3, c. 4. Figura además en un concierto efectuado el 2 de diciembre de 1860 en el que intervinieron las discípulas de canto de Inocencio Pellegrini y alumnos del Conservatorio Nacional de Música, en que se ejecutó el Himno a la caridad de Pellegrini, sobre un texto de Guillermo Matta, de acuerdo a El Ferrocarril, V/1521 (miércoles 21 de noviembre, 1860), p. 3, c. 1, y El Ferrocarril, V/1528 (jueves 29 de noviembre, 1860), p. 3, c. 5 . 
romántico Antonio Smith ${ }^{61}$, en las que seguramente se vinculó con el mundo literario del Chile de la época.

Olivia Sconcia es una soprano lírica nacida en Nueva York, en el seno de una familia de origen italiano, quien en 1861 llegó a Chile desde Lima con una compañía lírica, que se presentó triunfalmente en teatros de Santiago, La Serena y Copiapó para regresar a Valparaíso en enero de $1863^{62}$. En 1861 dio a conocer en Chile cinco composiciones. Tres de ellas, distribuidas en el país por Niemeyer e Inghirami, fueron muy posiblemente compuestas antes de su llegada al país. Ellas son La perla de Sevilla, vals [O-1], Le dernier adieu, marcha fúnebre [O-2], y una Romanza para soprano o tenor [O-3]. La segunda de ellas está dedicada "a la memoria de los heroes muertos en defensa de la libertad de Italia" ${ }^{63}$. Guarda relación en tal sentido con la obra anónima El suspiro de la Italia o la muerte de Cavour publicado el mismo año en Santiago y a la que se hizo referencia anteriormente. Las restantes dos obras fueron compuestas en Chile. Ellas son La estrella de Chile, vals para orquesta [O-4], y Adios a Chile, vals [O-5]. La primera de ellas fue anunciada para ser interpretada el martes 23 de julio de 1861 en un concierto a beneficio de Olivia Sconcia ${ }^{64}$. La segunda de ellas fue dedicada a Jesús Pérez, hija del recién electo Presidente José Joaquín Pérez ${ }^{65}$, sumándose así a muchos homenajes que le rindieran al Presidente liberal otros músicos residentes en Chile ${ }^{66}$. En un concierto a su beneficio la artista cantó este vals, instrumentado por Tulio Hempel, el que fuera "aplaudido con estrépito"67. A su regreso a Lima en 1863, junto con sus presentaciones de ópera italiana, continuó demostrando sus dotes como compositora. Con ocasión de su beneficio en esta ciudad, el 3 de octubre de 1863, se interpretó El Carolino, un vals de su autoría, en instrumentación para banda militar 68 .

Delfina Pérez es el pseudónimo de Delfina de la Cruz, quien estuvo muy vinculada al gran mundo político y militar de su época. Fue hija del General de División José María de la Cruz, muy relacionado con el mundo liberal chileno de mediados del siglo, y contrajo nupcias el año 1856 con Aníbal Pinto, Presidente de la República durante la época de la Guerra del Pacífico ${ }^{69}$. Calificada por el historiador Eugenio Pereira Salas como una "mujer culta y refinada, organizadora de interesantes veladas musicales”, estudió piano y composición con Giovanni

${ }^{61}$ Pereira Salas 1957:369; Pereira Salas 1978: 114-115.

${ }^{62}$ Pereira Salas 1857: 66-67.

${ }^{63}$ El Ferrocarril, VI/1675 (martes 21 de mayo, 1861), p. 3, c. 4.

${ }^{64}$ Según El Ferrocarril, VI/1723 (martes 16 de julio, 1861), p. 3, c. 4, el título de la obra es La bella santiaguina. En cambio, según El Ferrocarril, VI/1726 (viernes 19 de julio, 1861), p. 3, c. 4, el título de la obra es La estrella de Chile.

${ }^{65}$ El Ferrocarril, VI/1813 (viernes 1 de noviembre, 1861), p. 2, c. 5.

${ }^{66}$ Cf. Merino 2009: 36.

${ }^{67}$ Según El Ferrocarril, VI/1816 (martes 5 de noviembre, 1861), p. 3, c. 5, y El Ferrocarril, VI/1820 (sábado 9 de noviembre, 1861), p. 3, c. 1.

${ }^{68}$ Barbacci 1949: 498.

${ }^{69}$ Pereira Salas 1957:368. De ahí la dedicatoria de la polka militar ¡Viva mi comandante! [O-8, 1861] al Batallón Cívico $\mathrm{N}^{\circ} 1$ de Santiago, cuya banda la interpretara en público [El Ferrocarril, VI/ 1783 (viernes 27 de septiembre, 1861), p. 3, c. 3. 
Bayetti $^{70}$, y aparece mencionada entre las estudiantes que este profesor presentó en público el año $1853^{71}$. Destacada intérprete, su nombre aparece también vinculado al de Isidora Zegers, y al de otras damas de la alta sociedad chilena en conciertos de beneficencia efectuados en la década de $1850^{72}$.

Después de Isidora Zegers, Delfina Pérez fue la mujer que escribió el más alto número de obras en el siglo XIX. De Isidora Zegers se tiene un registro de 20 obras $^{73}$, mientras que de Delfina Pérez se guarda un registro de 12 obras. La diferencia yace en la comunicación al público. Según lo revela la tabla $N^{\circ} 3$, la obra de Delfina Pérez circuló en Santiago y Valparaíso. Pero además su polka para piano La estrella de la tarde fue tocada en París [O-1, 1856 ${ }^{74}$, y el vals para piano Armando el gondolero (Armando il gondoliero) [O-6, 1858] fue editado en Alemania en una tirada de quinientos ejemplares, presumiblemente por la empresa Niemeyer e Inghirami, de acuerdo a lo señalado anteriormente.

Tal como Isidora Zegers, Delfina Pérez cultivó la música para piano y la canción. Los comentarios de prensa se refirieron a Delfina Pérez como una compositora de nivel mucho más avanzado que las restantes creadoras materia del presente trabajo. En tal sentido el vals El copigüe [O-2, 1856] fue saludado como la pieza de "un nuevo talento musical" 75 y la redowa La sensitiva [O-3, 1857] fue anunciada como una "brillante redowa de salón"76. Asimismo, el schottisch para piano Le

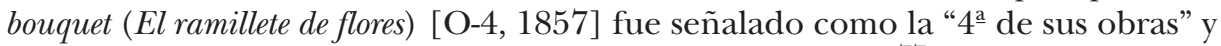
como "un tanto dificil por los muchos tonos que se mueve"77.

En la comunicación de sus canciones cumplió un papel muy importante la destacada cantante Luisa Correa de Tagle, "amiga y compañera de estudios" de Delfina Pérez de acuerdo a Eugenio Pereira Salas ${ }^{78}$. A esta última está dedicada la polka mazurka con variaciones La Calandria [O-5, 1857], quien además la cantó en un concierto anunciado para el 4 de noviembre de $1857^{79}$. La misma intérprete la cantó en un concierto anunciado para el 12 de agosto de $1862^{80}$, y tres años más tarde en otro concierto anunciado para el 31 de octubre de $1865^{81}$. En cuan-

${ }^{70}$ Pereira Salas 1978: 102.

${ }^{71}$ Pereira Salas 1957: 106.

${ }^{72} \mathrm{Al}$ respecto se puede señalar un concierto de beneficencia anunciado para el 1 de enero de 1854 [El Mensajero, I/185 (viernes 30 de diciembre, 1853), p. 3, c. 4.], IV/937 (jueves 30 de diciembre, 1858), p. 3, c. 1 y otro efectuado el 3 de enero de 1859 con ocasión de la inauguración del Asilo de la Casa de María al que asistiera el Arzobispo de Santiago [El Ferrocarril, IV/937 (jueves 30 de diciembre, 1858), p. 3, c. 1; IV/940 (lunes 3 de enero, 1859), p. 2, c. 7].

73 Merino 2008: 64-68.

${ }^{74}$ De acuerdo a El Ferrocarril, III/633 (martes 5 de enero, 1858), p. 3, c. 2.

${ }^{75}$ El Ferrocarril, I/ 28 (jueves 24 de enero, 1856), p. 3, c. 2.

${ }^{76}$ El Ferrocarril, II/335 (miércoles 21 de enero, 1857), p. 2, c. 5.

${ }^{77}$ El Ferrocarril, II/413 (miércoles 22 de abril, 1857), p. 3, c. 4. Otras referencias más genéricas figuran en Pereira Salas 1957: 368.

${ }^{78}$ Pereira Salas 1957: 368-369. El nombre lo señala como María Luisa Tagle. En las referencias de prensa que hemos consultado el nombre aparece como Luisa Correa de Tagle.

${ }^{79}$ El Ferrocarril, II/570 (viernes 24 de octubre, 1857), p. 3, cc. 3-4. De acuerdo a Pereira Salas 1957: 368-369, La Calandria es una tonada chilena.

${ }^{80}$ El Ferrocarril, VII/2044 (jueves 31 de julio, 1862), p. 3, c. 3.

${ }^{81}$ El Ferrocarril, X/3063 (martes 24 de octubre, 1865), p. 3, cc. 2-3. 
to al vals El pensamiento [O-7, 1858] fue interpretado por Luisa Correa de Tagle en un concierto efectuado en el mes de noviembre de $1858^{82}$.

Por otra parte, Delfina Pérez es la primera mujer chilena conocida que escribiera música para coros, una especie que hasta ese momento era un terreno privativo de los hombres. El Coro a la caridad [O-9, 1863] fue compuesto expresamente por Delfina Pérez para ser entonado en un gran concierto de beneficencia ${ }^{83}$. El Gran Coro La Filantropía [O-10, 1863], el que puede corresponder a la obra anterior, fue anunciado para ser interpretado en un concierto de beneficencia el 22 de agosto del mismo año ${ }^{84}$. Existe otra obra coral, titulada Himno a la industria, atribuida a Delfina Pérez por Eugenio Pereira Salas, la que habría obtenido un premio discernido en la Exposición de $1875^{85}$. No obstante, la única obra presentada a esta exposición bajo este título, y que fuera galardonada por el jurado, es de la autoría de Federico Guzmán ${ }^{86}$.

\section{PERSPECTIVAS}

En lo genérico, el presente trabajo permite reafirmar, en la perspectiva del Chile decimonónico, tres grandes tendencias señaladas por Pilar Ramos, que marcan en la actualidad la tónica de la relación de la mujer con la interpretación y la creación musical. Estas tendencias son las siguientes: (1) la menor inserción de las mujeres en las profesiones musicales, ya sea en la interpretación, en la dirección, en la composición o en la difusión; (2) la ratio femenina de la participación de la mujer en el cultivo de la composición la que es menor que en el cultivo de la interpretación; (3) la presencia aún más reducida de obras de autoras en las salas de concierto, dentro del ya reducido espacio reservado a la programación de compositores vivos.

Por otra parte, este estudio reafirma la necesidad que formula esta musicóloga de reconsiderar la significación de los espacios público y privado desde una perspectiva de género. Al respecto, importantes historiadores nacionales han planteado la relación de género que media entre el espacio público decimonónico y el espacio privado ${ }^{87}$. En lo que respecta a la creación musical en Chile, se puede afirmar que en el espacio público prevalece lo masculino, mientras que en el espacio privado prevalece lo femenino, en el período comprendido entre 1810 y 1855.

No obstante, se advierte un cambio en el período inmediatamente posterior, 1855-1869, en que la mujer irrumpe como creadora en el espacio público del país. Esta irrupción guarda relación con el aspecto civil más que con el aspecto político de este espacio, en el momento que la sociedad civil se constituye, desde mediados del siglo XIX, como una esfera independiente en el país ${ }^{88}$. Por otra

\footnotetext{
${ }^{82}$ El Ferrocarril, III/895 (jueves 11 de noviembre, 1858), p. 3, c. 1.

${ }^{83}$ El Ferrocarril, VIII/ 2357 (jueves 30 de julio, 1863), p. 3, c. 2.

${ }^{84}$ El Ferrocarril, VIII/2376 (viernes 21 de agosto, 1863), p. 3, c. 4.

${ }^{85}$ Cf. Pereira Salas 1957: 369 y Pereira Salas 1978: 103, i. 751.

${ }^{86}$ Merino 1993: 85-86.

${ }^{87}$ Serrano 2005: 139-140; Sanhueza 2005: 333-335.

${ }^{88}$ Sanhueza 2005:335.
} 
parte, desde una perspectiva de clase social, este proceso de inserción de la mujer en el espacio público como creadora estuvo reservado a los grupos más pudientes de la sociedad chilena decimonónica, cuyos miembros tuvieron mayor acceso a la educación y pudieron beneficiarse del desarrollo de la impresión y distribución de la música, dos factores claves que condicionan este cambio.

En otro orden de cosas, este proceso tiene que ver con un cambio de mentalidad, el que la historiadora Teresa Pereira Larraín plantea en los siguientes tér$\operatorname{minos}^{89}$ :

"Una nueva mentalidad va dando paso desde mediados del siglo XIX a un concepto de mujer más compañera del hombre, cuyo último fin ya no es buscar un marido para llegar al matrimonio y asegurarse un buen futuro. Las mujeres comienzan a soñar con otras perspectivas que las colocan, según ellas, en una situación más respetable, pues dejan de ser las eternas sometidas".

Con la gradual institucionalización de la vida musical chilena que se produce en el siglo XX, este cambio de mentalidad constituye el sustrato profundo de la inserción de la mujer como creadora en el espacio público, que ha sido analizado en profundidad por la destacada musicóloga chilena Raquel Bustos Valderrama ${ }^{90}$.

\section{BIBLIOGRAFÍA}

La bibliografía se divide en dos partes y contiene solamente ítems citados en el trabajo. En la primera parte se entrega un listado de diarios y revistas del siglo XIX ordenados alfabéticamente de acuerdo a la primera palabra del título, sea ésta sustantivo o artículo. En la segunda parte se entrega una lista de libros, artículos y monografías ordenadas alfabéticamente según el apellido del autor. Dos o más ítems bibliográficos escritos por un mismo autor se ordenan cronológicamente de acuerdo a la fecha de publicación

El Correo Literario, Santiago.

El Ferrocarril, Santiago.

El Mensajero, Santiago.

El Mercurio, Valparaíso.

Las Bellas Artes, Santiago.

II

BARBACCI, RODOlFo

1949 "Apuntes para un diccionario biográfico musical peruano", Fénix. Revista de la Biblioteca Nacional (Lima) Nº, pp. 414-510.

${ }^{89}$ Pereira Larraín 2007: 303.

${ }^{90} \mathrm{~A}$ modo de ejemplo, se puede hacer referencia a los excelentes trabajos sobre mujeres compositoras chilenas publicados por Raquel Bustos Valderrama en la Revista Musical Chilena entre 1978 y 2007 que se detallan en la bibliografía del trabajo. 
Bustos Valderrama, RaQuel

1978 "Ida Vivado Orsini”, RMCh, XXXII/142-144 (abril-diciembre), pp. 106-112.

1981 "María Luisa Sepúlveda Maira (1892-1958)", RMCh, XXXV/153-155 (eneroseptiembre), pp. 117-140.

1982 "Marta Canales Pizarro (1895-)”, RMCh, XXXVI/157 (enero-junio), pp. 40-64.

1983 “Carmela Mackenna Subercaseaux”, RMCh, XXXVII/159 (enero-junio), pp. 50-75.

1989 “Ida Vivado Orsini (1908-1989). In memoriam”, RMCh, XLIII/172 (julio-diciembre), p. 126.

2007 “Leni Alexander Pollack (1924-2005)”, RMCh, LXI/207 (enero-junio), pp. 28-70.

GAZMURi, Cristián

1992 El "48" chileno: igualitarios, reformistas, radicales, masones y bomberos. Santiago: Editorial Universitaria.

Merino Montero, Luis

1993 "Tradición y modernidad en la creación musical: la experiencia de Federico Guzmán en el Chile independiente”, RMCh, XLVII/179 (enero-junio), pp. 5-68; XLVII/180 (julio-diciembre), pp. 69-148. Hay tirada aparte.

2006 "La Sociedad Filarmónica de 1826 y los inicios de la actividad de conciertos públicos en la sociedad civil de Chile hacia 1830”, RMCh, LX/206 (julio-diciembre), pp. 5-27.

2008 "Isidora Zegers y José Zapiola: convergencias y diferencias en el advenimiento de la modernidad en la sociedad civil del Chile republicano (1810-1855)", Cuadernos de Música Iberoamericana, volumen 15, segunda época. Madrid: Instituto Complutense de Ciencias Musicales, pp. 41-73.

2009 "El surgimiento de la Sociedad Orfeón y el periódico Las Bellas Artes. Su contribución al desarrollo de la actividad musical y de la creación decimonónica en Chile”, Revista Neuma, II/2009. Universidad de Talca, Escuela de Música, pp. 11-43.

Pereira Larraín, Teresa

2007 Afectos e intimidades. Santiago: Ediciones Universidad Católica de Chile.

Pereira Salas, Eugenio

1957 Historia de la música en Chile (1850-1900). Santiago: Publicaciones de la Universidad de Chile.

1978 Biobibliografía musical de Chile desde los orígenes a 1886 [Serie de Monografías Anexas a los Anales de la Universidad de Chile]. Santiago: Ediciones de la Universidad de Chile.

Sanhueza, Carlos

2005 "El problema de mi vida: ¡soy mujer! Viaje, mujer y sociedad", en Rafael Sagredo y Cristián Gazmuri (editores). Historia de la vida privada en Chile. Tomo II. El Chile moderno de 1840 a 1925. Santiago: Taurus, pp. 333-347.

SERrano, Sol

2005 "La privatización del culto y la piedad católicas", en Rafael Sagredo y Cristián Gazmuri (editores), op. cit., pp. 139-155. 
TORRES, RODRIGO

2008 "Zamacueca a toda orquesta. Música popular, espectáculo público y orden republicano en Chile (1820-1860)", RMCh, LXII/209 (enero-junio), pp. 5-27.

Tupper de Bianchi, Flora

s.f. Mis confidencias. Copia de apuntes de mi abuela paterna doña Flora Tupper de Bianchi. Corpus de mujer. Biblioteca electrónica. Escritura de mujeres en Chile. Siglo XIX en www.corpus-de-mujer.cl.

\section{Catálogo}

\section{Notas preliminares}

1. El presente catálogo contiene un listado de las obras a que se hace referencia en este trabajo.

2. Las obras se ordenan alfabéticamente de acuerdo al apellido paterno de la autora o, en subsidio, del apellido de casada, en caso que el anterior se desconozca. Se han colocado al inicio las obras publicadas de manera anónima.

3. Considerando la escasez de material disponible acerca de las compositoras, se incluye en el catálogo la información pertinente extractada de los periódicos de la época, sin perjuicio de que dicha información aparezca además en el texto del trabajo.

Abreviaturas

AE Valparaíso, Almacén de Música de Augusto Eggeling.

AF Santiago, Agencia del Ferrocarril, Calle de los Huérfanos.

AS Santiago, Litografía de A. Saling, Plaza del Teatro.

BA Santiago, Periódico Las Bellas Artes.

BCUCH-EPS Biblioteca Central de la Universidad de Chile, donación Eugenio Pereira Salas.

BMCH Eugenio Pereira Salas. Biobibliografía musical de Chile desde los orígenes a 1886 [Serie de Monografias Anexas a los Anales de la Universidad de Chile]. Santiago: Ediciones de la Universidad de Chile, 1978.

CL Santiago, Periódico El Correo Literario.

EG Santiago, Litografía y Almacén de Eustaquio Guzmán, Pasaje Bulnes № 47.

FG

IP Santiago, Litografía de Fernando A. Guzmán.

JK Santiago, Tienda de Inocencio Pellegrini, calle Ahumada. Santiago, Almacén de Música Juan Krause, Portal Viejo, Calle del Estado. Valparaíso, La Mariposa, "periódico quincenal de modas, costumbres i amena literatura".

LME Valparaíso, Librería del Mercurio.

LS Litografía de Stople.

LSV Valparaíso, Litografía Lebas Sucesor.

NA Santiago, Nicolás Anrique, Calle de la Compañía, № 81.

NIS Santiago, Almacén de Música Niemeyer e Inghirami, Calle del Estado.

NIV Valparaíso, Almacén de Música Niemeyer e Inghirami, Calle del Cabo № 17.

PC Santiago, Litografía de Pedro [=Pierre André] Cabot, Calle del Estado $N^{\circ} 40$, frente a la Galería Bulnes.

Pf pianoforte.

RPS Santiago, Almacén Francisco Risso Patrón, Calle de los Huérfanos № 190.

RPV Valparaíso, Almacén Baldomero Risso Patrón, Calle del Cabo.

s.f. Sin fecha. 
TS

$\mathrm{V}$

VV

ANÓNIMO 1861

[O-1] El suspiro de la Italia o la muerte de Cavour, 1861, Obs: anunciada la publicación en fecha próxima por El Ferrocarril, VI/1740 (lunes 5 de agosto, 1861), p. 3, c. 2. La autora es descrita como "una señorita de esta capital, entusiasta por la Independencia de la Italia, i admiradora del gran patriota que esta nación acaba de perder".

ANÓNIMO 1862

[O-1] Último adiós, gran vals, pf, 1862, Ed: NIS, precio 60 centavos, Obs: anunciado en El Ferrocarril, VII/2153 (miércoles 3 de diciembre, 1862), p. 3, c. 3, como habiendo sido compuesta por "una señorita", dedicado a Guillermo Lees.

ANÓNIMO 1864

[O-1] El voluntario, vals, 1864, Ed: NIS, NIV, RPS, RPV, Obs: anunciada en El Ferrocarril, IX/2662 (viernes 8 de julio, 1864), p. 3, c. 3, como un "valse dedicado a la entusiasta juventud de Santiago i Valparaiso, compuesto por una señorita hija de un veterano de la Independencia”.

L. R. DE P. 1864

[O-1] La aristócrata, polka, 1864, Ed: distribución por NA, Obs: anunciada en El Ferrocarril, IX/2792 (jueves 8 de diciembre, 1864), p. 3, c. 5.

A.C. DE ARAna 1856

[O-1] La luna de invierno, polka, 1856, Ed: Album Musical de Señoritas, № 8, Obs: se anuncia su reciente publicación en El Ferrocarril, I/219 (jueves 4 de septiembre, 1856), p. 3, c. 6, Ref: BMCH, p. 31, i. 221.

Manuela Barros Urmeneta 1861

[O-1] Salve a la Virgen, V, 1861, Obs: anunciada en El Ferrocarril, VI/1819 (viernes 8 de noviembre, 1861), p. 3, c. 3, en que se informa acerca de la interpretación de la obra esa noche por el joven Osbaldo Uriondo en la celebración del Mes de María en la Iglesia de la Compañía.

Cecilia Besa 1864

[O-1] La Salvadora, polka mazurka, 1864, Obs: anunciada como la obra de "una señorita aficionada" en El Ferrocarril, IX/2621 (sábado 28 de mayo, 1864), p. 2, c. 6, p. 3, c. 1. Obra dedicada a la Primera Compañía de Bomberos.

ECLetra de Ferrari 1869

[O-1] La Orfeonista, polka mazurka, 1869, Ed: BA, Obs: anunciada en BA, I/13 (28 de junio, 1869), p. 68, como "una preciosa composición”. Fue anunciada además en El Ferrocarril, XIV/4352 (domingo 17 de octubre, 1869), p. 3, c. 6.

Florentina G. De Dueñas 1865

[O-1] La Esmeralda, vals, pf, 1865, Ed: PC, Obs: anunciada por El Ferrocarril, X/3101 (jueves 7 de diciembre, 1865), p. 3, c. 4. La autora dedica la obra a Juan Williams Rebolledo, vencedor de la Covadonga. Los dineros recaudados por la edición eran pro fondos de la guerra entre Chile y España.

Mercedes de la Cuadra de Correa 1869

[O-1] Mi delirio, vals brillante, 1869, Ed: Distribuido por JK, Obs: anunciada en El Ferrocarril, XIV/4604 (viernes 17 de diciembre, 1869), p. 3, c. 6, y El Ferrocarril, XIV/ 
4605 (sábado 18 de diciembre, 1869), p. 3, c. 3, con la información que se trata de su primer trabajo.

Domitila M. GaCitúa 1865

[O-1] Alerta, polka mazurka, pf, 1865, Ed: se informa su distribución por JK, Obs: anunciada en El Ferrocarril, X/3081 (martes 14 de noviembre, 1865), p. 3, c. 3, como el primer ensayo de la compositora. Los dineros recaudados por la edición eran pro fondos de la guerra entre Chile y España.

ELVIRA HonOrato 1866

[O-1] Schottish, pf, 1866, Ed: distribuido en Santiago por JK y NIS; en Valparaíso, por AE y NIV, Obs: anunciada en El Ferrocarril, XI/3131 (11 de enero, 1866), p. 3, c. 6, como un "Homenaje al comandante Williams Rebolledo". El Ferrocarril, XI/3132 (viernes 12 de enero, 1866), p. 3, c. 3, informa acerca de la edad de la compositora (14 años), y que los dineros recaudados por la edición eran pro fondos de la guerra entre Chile y España.

CARMEla InSUNZA (=INSURZA) 1866-1867

[O-1] La dictadura peruana, polka, pf, 1866, Ed: se informa su distribución por almacenes de música en Santiago y Valparaíso, Obs: anunciada en El Ferrocarril, XI/3427 (sábado 22 de diciembre, 1866), p. 3, c. 4, como una "obra dedicada al señor don Mariano Ignacio Prado, dictador del Perú”. En El Ferrocarril, XI/3429 (lunes 24 de diciembre, 1866), p. 3, c. 4, se indica que es una composición amateur. En $E l$ Ferrocarril, XII/3460 (jueves 24 de enero, 1867), p. 3, c. 2, se cita la carta de la compositora a Prado y la respuesta de este último agradeciéndola.

[O-2] La estrella de la mañana, vals, 1867, Ed: LS, Obs: anunciada en El Ferrocarril, XII/ 3707 (viernes 4 de octubre, 1867), p. 2, c. 6. De los conocimientos musicales de la autora señala que "son bastante sobresalientes i harto conocidos del público".

EleOdora ÍñIgUEZ de CARMONA 1867

[O-1] El poeta, vals, 1867, Ed: se anuncia su distribución por JK y LME por un precio de 60 centavos, Obs: Anunciada en El Ferrocarril, XII/3572 (sábado 18 de mayo, 1867), p. 3, c. 6, como una obra "dedicada al distinguido vate chileno don Eduardo de la Barra, por una señorita porteña”. En El Ferrocarril, XII/3587 (domingo 2 de junio, 1867), p. 2, c. 5, se indica que la obra es un obsequio "a nuestro elegante poeta don Eduardo de la Barra con motivo de unos versos que éste le habia dedicado el año anterior".

RAFAELA LAISECA 1856

[O-1] La constitución granadina, polka, 1856, Ed: AS, EG, venta por 50 centavos; Pres: BCUCH-EPS, Obs: anunciada en ElFerrocarril, I/292 (martes 2 de diciembre, 1856), p. 3, c. 6, en que se informa acerca de "otra edición, con la misma carátula, pero impresa en la litografía de A. Saling [AS], plaza del Teatro”, Ref: BMCH, p. 89, i. 662 .

Amelia [= Amalia] LanZa 1863

[O-1] Polka-mazurka, 1863, Ed: LMA, Obs: según El Ferrocarril, VII/2326 (jueves 25 de junio, 1863), p. 3, c. 2, la obra, identificada como una "brillante mazurca", aparece en el tercer número de La Mariposa. Por otra parte El Ferrocarril, VIII/2298 (sábado 23 de mayo, 1863), p. 3, c. 5, la identifica como "polka mazurka" y anuncia la publicación para el segundo número. 
Delfina Pérez [=Delfina Cruz] 1856-1886

[O-1] La estrella de la tarde, polka, pf, 1856, Ed: EG, precio 75 centavos, Obs: anunciada en ElFerrocarril, I/21 (miércoles 16 de enero, 1856), p. 3, cc. 5-6. El Ferrocarril, III/ 633 (martes 5 de enero, 1858), p. 3, c. 2, informa que la obra se ha tocado en París, Ref: BMCH, p. 102, i. 744.

[O-2] El copigüe, vals, 1856, Ed: FG, Obs: la primera y única obra de la compositora anunciada bajo el nombre de Delfina Cruz, en El Ferrocarril, I/28 (jueves 24 de enero, 1856), p. 3, c. 2, en que se destaca como "un nuevo talento musical". Dedicado a Mercedes Pinto, Ref: BMCH, p. 102, i. 745.

[O-3] La sensitiva, redowa, pf, 1857, Ed: editada y distribuida a través de los siguientes puntos de venta, según El Ferrocarril, II/343 (viernes 30 de enero, 1857), p. 3, c. 6. "en la esquina del portal, sobre la calle Ahumada y en la ajencia del Ferrocarril, calle de los Huérfanos [AF]. En Valparaíso, en el almacén de música de Eduardo Niemeyer Inghirami, calle del Cabo, num. 17 [NIV]", Obs: anunciada en El Ferrocarril, II/335 (miércoles 21 de enero, 1857), p. 2, c. 5, como una "brillante redowa de salon”, “dedicada a la Srta. Luisa Correa”, Ref: BMCH, pp. 102, i. 746.

[O-4] Le bouquet, El ramillete de flores, pf, schottisch, 1857, Ed: editado y distribuido a través de los siguientes puntos de venta: en Santiago, EG, IP, TS; en Valparaíso, NIV, Obs: anunciada en El Ferrocarril, II/413 (miércoles 22 de abril, 1857), p. 3, c. 4, como la "4⿳亠丷a de sus obras" y como "un tanto difícil por los muchos tonos en que se mueve”, Ref: BMCH, p. 103, i. 747 con la información de su dedicatoria a María Mercedes Correa y su depósito en la Biblioteca Nacional en 1857.

[O-5] La Calandria, polka-mazurka con variaciones, V, 1857, Obs: de acuerdo a El Ferrocarril, II/570 (viernes 24 de octubre, 1857), p. 3, cc. 3-4, la obra está dedicada a Luisa Correa de Tagle, quien la cantó en un concierto anunciado para el 4 de noviembre en el Teatro Municipal. Se volvió a cantar por la misma intérprete en 1862, según El Ferrocarril, VII/2044 (jueves 31 de julio, 1862), p. 3, c. 3 en un concierto anunciado para el 12 de agosto, y en 1865 en un concierto anunciado para el 31 de octubre de acuerdo a El Ferrocarril, X/3063 (martes 24 de octubre, 1865), p. 3, cc. 2-3, Ref: BMCH, p. 103, i. 748.

[O-6] Armando el gondolero (Armando il gondoliero), vals, pf, 1858, Ed: editado en Alemania en una tirada de quinientos ejemplares, de acuerdo a El Ferrocarril, III/633 (martes 5 de enero, 1858), p. 3, c. 2, presumiblemente por NIS o NIV, Pres: BCUCH-EPS, Ref: BMCH, p. 103, i. 752.

[O-7] El pensamiento, vals, V, 1858, Obs: según El Ferrocarril, III/895 (jueves 11 de noviembre, 1858), p. 3, c. 1, la obra fue interpretada por Luisa Correa de Tagle en un concierto efectuado ese mes.

[O-8] ¡Viva mi comandante!, polka militar, 1861, Ed: PC, Obs: anunciada en El Ferrocarril, VI/1783 (viernes 27 de septiembre, 1861), p. 3, c. 3, señalando además que está dedicada al Batallón Cívico número 1 de Santiago, el que la ha ejecutado.

[O-9] Coro a la caridad, VV, 1863, Obs: de acuerdo a ElFerrocarril, VIII/2357 (jueves 30 de julio, 1863), p. 3, c. 2, la obra fue compuesta expresamente por Delfina Pérez para ser entonada ese mes en un gran concierto de beneficencia.

[O-10] Gran Coro La Filantropía,VV, 1863, Obs: de acuerdo a El Ferrocarril, VIII/2376 (viernes 21 de agosto, 1863), p. 3, c. 4, la obra se anuncia para ser interpretada en un concierto de beneficencia el 22 de agosto. Es posible que corresponda a la misma 
obra antes señalada [O-9], por la cercanía de las fechas en que se anuncia la realización del concierto de beneficencia. Bajo el título Coro de la Filantropía, es interpretada por un grupo de señoritas y caballeros en un concierto de beneficencia efectuado el miércoles 18 de octubre, 1871, en el Club de la Reforma. En la crítica del concierto, aparecida en El Ferrocarril, XVI/4967 (sábado 21 de octubre, 1871), p. 3, cc. 2-3, es calificado como "música grave i agradable".

[O-11] La flor del alma, vals, s.f., Ed: Santiago, Litografía Guzmán (EG o FG), Pres: BCUCHEPS, Obs: dedicado a la Sociedad "Del Porvenir", Ref: BMCH, p. 103, i. 750, con la información de una segunda edición en Santiago, 1886.

[O-12] La noche, redowa, s.f., Ed: LSV; además venta en los almacenes de música en general al precio de 25 centavos, Pres: BCUCH-EPS, Ref: BMCH, p. 103, i. 749.

Eufrasia Prieto 1863

[O-1] Matilde, redowa, 1863, Ed: editada como suplemento musical de LMA, I/15 (22 de diciembre, 1863), Obs: anunciada en El Ferrocarril, VIII/2484 (sábado 26 de diciembre, 1863), p. 3, c. 1, Ref: BMCH, p. 105, i. 767.

María Luisa PRieto 1856

[O-1] La simpatía, polka, 1856, Ed: Album Musical de Señoritas, № 12, Obs: anunciada en El Ferrocarril, I/283 (viernes 21 de noviembre, 1856), p. 3, c. 2, como una obra dedicada a la Sra. Manuela Correa de Ovalle e identificando a la autora como residente en Valparaíso, Ref: BMCH, p. 105, i. 766.

Olivia SCONCIA 1861

[O-1] La perla de Sevilla, vals, 1861, Ed: NIS, Obs: anunciada en El Ferrocarril, VI/ 1675 (martes 21 de mayo, 1861), p. 3, c. 4.

[O-2] Le dernier adieu, marcha fúnebre, 1861, Ed: NIS, Obs: anunciada en El Ferrocarril, VI/ 1675 (martes 21 de mayo, 1861), p. 3, c. 4, identificando a la autora como prima donna de la Compañía Lírica, e informando que está dedicada "a la memoria de los heroes muertos en defensa de la libertad de Italia".

[O-3] Romanza, S o T, 1861, Ed: NIS, Obs: anunciada en El Ferrocarril, VI/ 1675 (martes 21 de mayo, 1861), p. 3, c. 4.

[O-4] La estrella de Chile, vals, Orq, 1861, Obs: anunciada para ser interpretada el martes 23 de julio en un concierto a beneficio de Olivia Sconcia según El Ferrocarril, VI/ 1723 (martes 16 de julio, 1861), p. 3, c. 4, bajo el título La bella santiaguina, y bajo el título La estrella de Chile, según ElFerrocarril, VI/1726 (viernes 19 de julio, 1861), p. 3 , c. 4.

[O-5] Adiós a Chile, vals, 1861, Ed: PC, Pres: BCUCH-EPS, Obs: anunciada en El Ferrocarril,VI/1813 (viernes 1 de noviembre, 1861), p. 2, c. 5; dedicado a Jesús Pérez, hija del Presidente José Joaquín Pérez. En un concierto a su beneficio la artista cantó este vals, instrumentado por Tulio Hempel, siendo "aplaudido con estrépito", según El Ferrocarril, VI/1816 (martes 5 de noviembre, 1861), p. 3, c. 5 y El Ferrocarril, VI/1820 (sábado 9 de noviembre, 1861), p. 3, c. 1, Ref: BMCH, p. 113 , i. 825 .

ANA [ANNA] SMITh IRISARRI 1858

[O-1] La sonrisa, polka elegante, pf, 1858, Ed: EG, distribuida por IP, precio 50 centavos, Pres: BCUCH-EPS, Obs: anunciada en El Ferrocarril, III/775 (martes 22 de junio, 1858), p. 3, c. 3 y El Ferrocarril, III/ 789 (jueves 8 de julio, 1858), p. 3, c. 7, dedicada a la hermana de la autora, Elena Smith de Mouat, Ref: BMCH, p. 115, i. 834. 
[O-2] La separación, canción, V, 1858, Ed: editada por EG, como suplemento musical de CL, I/5 (14 de agosto, 1858), Obs: basada en una poesía de Guillermo Blest Gana, Ref: BMCH, p. 115, i. 832.

[O-3] La pensativa, polka-mazurka, 1858, Ed: editada por EG, Obs: anunciada en ElFerrocarril, III/858 (miércoles 29 de septiembre, 1858), p. 2, c. 7, dedicada a la Sociedad de Beneficencia de Señoras de Santiago, Ref: BMCH, p. 115, i. 833. 